\title{
Human Cytomegalovirus-stimulated Peripheral Blood Mononuclear Cells Induce HIV-1 Replication via a Tumor Necrosis Factor- $\alpha$-mediated Mechanism
}

\author{
Phillip K. Peterson, ${ }^{\star \star}$ Genya Gekker, ${ }^{\star \neq}$ Chun C. Chao, ${ }^{\star \star}$ Shuxian Hu, ${ }^{\star \ddagger}$ Charlene Edelman, ${ }^{\star \$}$ \\ Henry H. Balfour, Jr.,"\$ and Jan Verhoefl" \\ ${ }^{*}$ Department of Medicine, Hennepin County Medical Center, Minneapolis, Minnesota 55415; ${ }^{\ddagger}$ University of Minnesota Medical School, \\ Minneapolis, Minnesota 55455; ${ }^{\circledR}$ Departments of Laboratory Medicine and Pathology and Pediatrics, University Health Sciences Center, \\ Minneapolis, Minnesota 55455; and Department of Medical Microbiology, University of Utrecht, Utrecht, The Netherlands
}

\begin{abstract}
Human cytomegalovirus (HCMV) is a potential cofactor in HIV-1 infection. To investigate the mechanism whereby HCMV promotes HIV-1 replication, a PBMC coculture assay which measures HIV-1 p24 antigen release was used as an index of viral replication. HCMV-stimulated PBMC were capable of inducing HIV-1 replication in cocultures with acutely infected PBMC; however, this occurred only when the PBMC were from HCMV-seropositive donors $(598 \pm 207$ versus $27 \pm 10 \mathrm{pg} / \mathrm{ml} \mathrm{p} 24$ antigen with PBMC from HCMV-seronegative donors on day 6 of coculture). Upon stimulation with HCMV, PBMC obtained exclusively from HCMV-seropositive donors released tumor necrosis factor (TNF)- $\alpha(270 \pm 79$ $\mathrm{pg} / \mathrm{ml}$ at $18 \mathrm{~h}$ of culture). Monoclonal antibodies to TNF- $\alpha$ blocked the activity of HCMV-stimulated PBMC in cocultures both with acutely HIV-1-infected PBMC and with the chronically infected promonocytic line U1. Also, treatment of HCMV-stimulated PBMC with pentoxifylline, an inhibitor of TNF- $\alpha$ mRNA, markedly reduced HIV-1 replication in cocultures both with acutely and chronically infected cells. These results indicate that TNF- $\alpha$ is a key mediator of HIV-1 replication induced by HCMV-stimulated PBMC and support the concept that this cytokine plays an important role in the pathogenesis of HIV-1 infection. (J. Clin. Invest. 1992. 89:574580.) Key words: AIDS • cytokines • interleukins • pentoxifylline $\cdot$ viral infection
\end{abstract}

\section{Introduction}

One of the notable features of HIV-1 infection is its prolonged incubation period during which the virus is harbored in a quiescent state in CD4 lymphocytes and mononuclear phagocytes. Soon after recognition of the etiologic role of HIV-1 in AIDS, investigators began to search for cofactors, i.e., agents that could accelerate progression by upregulating expression of HIV-1 in chronically infected cells (1). Human cytomegalovirus (HCMV), ${ }^{1}$ a cause of serious opportunistic infection in

Address reprint requests to Dr. Phillip K. Peterson, Department of Medicine, Hennepin County Medical Center, 701 Park Avenue, Minneapolis, MN 55415.

Received for publication 31 May 1991 and in revised form 12 September 1991.

1. Abbreviations used in this paper: HCMV, human cytomegalovirus; $\mathrm{TCID}_{50}, 50 \%$ tissue culture infectious dose; TNF, tumor necrosis factor; $\mathrm{VZV}$, varicella zoster virus.

J. Clin. Invest.

(c) The American Society for Clinical Investigation, Inc.

0021-9738/92/02/0574/07 \$2.00

Volume 89, February 1992, 574-580
AIDS patients (2-4), has been proposed to act as such a cofactor. Although there are contradictory reports $(5,6)$, coinfection with HCMV has been found by some investigators to adversely influence the course of HIV-1-related disease (7-9).

Support for HCMV as a cofactor has been provided by in vitro studies demonstrating increased HIV-1 replication or cytopathogenicity in certain $\mathrm{T}$ lymphocyte lines upon stimulation with HCMV (10-12). Also, HCMV has been shown to stimulate HIV-1 replication in PBMC cultures from HIV-1-infected donors (13). The mechanism underlying these HCMVmediated effects has not been established; however, cytokines that promote HIV-1 expression have been considered to play an important role (11). In the present study, we used a PBMC coculture assay to investigate the mechanism whereby HCMV stimulates HIV-1 replication. We hypothesized that upon stimulation with HCMV, PBMC would yield a cytokine that serves as a mediator of HIV-1 replication. Our findings point to a key role of tumor necrosis factor (TNF)- $\alpha$ in this phenomenon.

\section{Methods}

Reagents. LPS was obtained from Sigma Chemical Co. (St. Louis, MO). Recombinant TNF- $\alpha$ was the gift of R \& D Systems, Inc. (Minneapolis, MN). Anti-TNF- $\alpha$ antibodies (mouse monoclonal antibody, immunoglobulin $[\mathrm{Ig}] \mathrm{G}_{1}$ ) specific for human natural and recombinant TNF- $\alpha$ were kindly provided by Dr. R. Torensma (University of Utrecht, Utrecht, The Netherlands). Mouse $\mathrm{IgG}_{1}$ monoclonal antibody of irrelevant specificity was purchased from Sigma Chemical Co. Pentoxifylline was the gift of Dr. W. J. Novick (Hoechst-Roussel Pharmaceuticals, Inc., Somerville, NJ).

Viral isolates and HIV-1-infected cells. The laboratory-adapted HCMV strain AD169 (American Type Culture Collection, Rockville, MD) was grown in human foreskin fibroblasts (University of Minnesota strain D) and stored in aliquots in liquid nitrogen. The $50 \%$ tissue culture infectious dose $\left(\right.$ TCID $\left._{50}\right)$ was determined for the HCMV stock $\left(10^{-6.5}\right.$ endpoint) before experimental testing, and concentrations of $10^{-2.5}, 10^{-3.5}$, and $10^{-4.5}$ TCID $_{50}$ were used to stimulate PBMC. Varicella zoster virus (VZV) strain Oka (American Type Culture Collection) was also grown in human foreskin fibroblasts, and after determining the $\operatorname{TCID}_{50}$ of the VZV stock $\left(10^{-4}\right.$ endpoint), concentrations of $10^{-1}, 10^{-2}$, and $10^{-3} \mathrm{TCID}_{50}$ were used to stimulate PBMC. Virus stocks were determined to be mycoplasma-free by a commercial screening system (Bionique Laboratories, Inc., Saranac Lake, NY). Acutely HIV-1-infected PBMC were prepared using previously described methods (14) by incubating a cryopreserved stock of HIV-1, isolated from an asymptomatic patient, for $2 \mathrm{~h}$ with a freshly thawed aliquot of cryopreserved PBMC that had been obtained from a single HIV-1-seronegative donor. The chronically HIV-1-infected promonocytic line U1 was kindly provided by the National Institute of Allergy and Infectious Diseases (Bethesda, MD).

$P B M C$ donors, preparation, and treatments. Healthy laboratory personnel with no known risk factors for HIV-1 infection were recruited as donors of heparinized venous blood for isolation of PBMC as previously described (14). Serum samples from these donors were tested for HIV-1 antibody titers by ELISA, for HCMV antibody titers 
by latex agglutination assay, and for VZV by ELISA. All donors were HIV-1 seronegative. HCMV reciprocal antibody titers $<4$ were classified as negative, and antibody titers $\geq 4$ were considered positive. HCMV antibody titers $=4$ were confirmed to be positive by ELISA. PBMC were added to wells of 24 -well culture plates $\left(1 \times 10^{6}\right.$ cells/well $)$ containing $2 \mathrm{ml}$ of culture medium that consisted of RPMI 1640 (Gibco Laboratories, Grand Island, NY), $2 \mathrm{mM}$ glutamine, 10\% heatinactivated pooled human $\mathrm{AB}$ serum (Pel-Freeze Biologicals, Rogers, AZ), $200 \mathrm{U} / \mathrm{ml}$ of penicillin, and $200 \mu \mathrm{g} / \mathrm{ml}$ of streptomycin. The pooled human $\mathrm{AB}$ serum used in the culture medium had a HCMV titer of 64 . The culture medium used in this study contained undectable amounts of endotoxin $(<0.25 \mathrm{U} / \mathrm{ml})$ by Limulus amebocyte lysate assay (Associates of Cape Cod, Inc., Woods Hole, MA), kindly performed by S. Kraft (Regional Kidney Dialysis Program, Minneapolis, $\mathrm{MN}$ ).

Treatments of PBMC consisted of incubation $\left(37^{\circ} \mathrm{C}, 5 \% \mathrm{CO}_{2}\right)$ of cells for $3 \mathrm{~h}$ with HCMV, VZV (each at the indicated TCID $_{50}$ doses), LPS $(1 \mathrm{ng} / \mathrm{ml})$, or culture medium alone, followed by washing and resuspension of PBMC in fresh culture medium. In studies with antiTNF- $\alpha$ antibodies, PBMC were treated with equal concentrations of specific $\mathrm{IgG}_{1}$ (stock concentration at $10 \mathrm{mg} / \mathrm{ml}$ ) or control $\mathrm{IgG}_{1}$ mono- $^{-}$ clonal antibodies for $30 \mathrm{~min}$ before stimulation with HCMV. In experiments with pentoxifylline, $\mathrm{PBMC}$ were incubated for $30 \mathrm{~min}$ in culture medium containing varying concentrations of drug before stimulation with HCMV. Antibodies and pentoxifylline were maintained at indicated concentrations in all subsequent culture steps.

Cytokine determinations. PBMC which had been treated with HCMV, LPS, or culture medium alone were cultured $\left(37^{\circ} \mathrm{C}, 5 \% \mathrm{CO}_{2}\right)$ for indicated times, and after centrifugation, $1.0 \mathrm{ml}$ supernatant samples were removed and kept frozen $\left(-70^{\circ} \mathrm{C}\right)$ until assayed for interleukin (IL)-1 $\beta$, IL-6, and TNF- $\alpha$ levels using an ELISA specific for each cytokine ( $\mathrm{R} \& \mathrm{D}$ Systems).

Cocultures of PBMC and HIV-1-infected cells. PBMC which had been treated with HCMV, VZV, or with culture medium alone for $72 \mathrm{~h}$ were added to wells of 24-well plates that had been seeded with $5 \times 10^{5}$ acutely HIV-1-infected PBMC or with $5 \times 10^{3} \mathrm{U} 1$ cells. Cocultures with acutely HIV-1-infected PBMC contained $1 \times 10^{6}$ donor PBMC; cocultures with $\mathrm{U} 1$ cells contained $1 \times 10^{4}$ donor PBMC. After incubation $\left(37^{\circ} \mathrm{C}, 5 \% \mathrm{CO}_{2}\right)$ for the indicated number of days, $0.3 \mathrm{ml}$ of supernatant samples were taken from the cocultures and were stored $\left(-20^{\circ} \mathrm{C}\right)$ until assayed for HIV $-1 \mathrm{p} 24$ antigen levels, which were used as an index of HIV-1 replication in cocultures containing acutely infected cells and of HIV-1 expression in cocultures containing U1 cells.

HIV-1 antigen assay. HIV-1 antigen levels were measured using an ELISA that detects mainly HIV-1 p24 antigen (Abbott Laboratories, North Chicago, IL). A standard curve derived from known amounts of p24 antigen was used to quantity the antigen in coculture supernatants. In each experiment background values, obtained from readings derived from supernatants of wells containing noninfected PBMC, were subtracted from experimental values.

Statistical methods. Where appropriate, data were expressed as mean \pm SE. For comparison of means of two groups, statistical significance was assessed by Student's $t$ test. Repeated measures analysis of variance was used to evaluate the effects of antibodies or pentoxifylline using SPSS (SPSS, Inc., Chicago, IL).

\section{Results}

$H I V-1$ replication in cocultures containing acutely infected $P B M C$. To determine whether HCMV promotes HIV-1 replication in cocultures with acutely infected cells, PBMC from a total of 16 healthy donors were cocultured with HIV-1-infected PBMC. Eight of these donors were HCMV seropositive, and eight were HCMV seronegative. Results of experiments from representative donors are shown in Fig. 1. In the absence of HCMV, cocultures with PBMC from all 16 donors showed little or no evidence of HIV-1 replication after 7 d (p24 antigen levels in supernatants were either undetectable or $<100 \mathrm{pg} /$ ml). Similarly, when PBMC from the eight HCMV-seronegative donors were treated with $\mathrm{HCMV}$, there was no evidence of HIV-1 replication regardless of the HCMV concentration used (Fig. $1 A$ ). In contrast, when PBMC from the eight HCMVseropositive donors were treated with HCMV, release of HIV-1 p24 antigen into coculture supernatants was detected in every case. The amount of p24 antigen, however, varied among the HCMV-seropositive donors and was dependent upon the dose of HCMV used to stimulate the cells (Fig. 1, $B-D$ ). On day 6 of

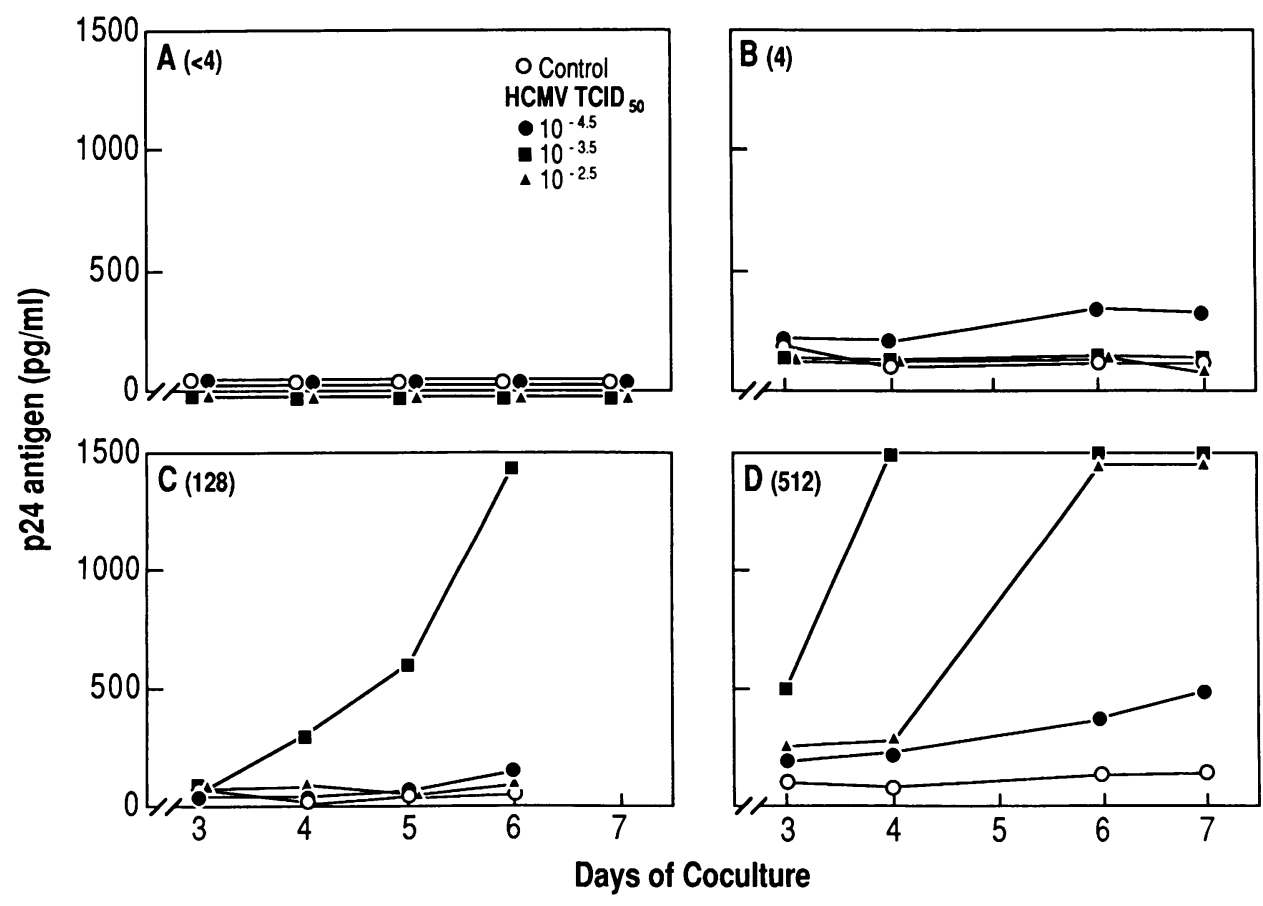

Figure 1. HIV-1 replication in cocultures containing HCMV-treated PBMC. HCMV antibody titers for each of four PBMC donors $(A-D)$ are given in parentheses. Data from donor $A$ are representative of findings with PBMC from eight HCMV-seronegative donors; data from donors $B-D$ are representative of findings with PBMC from eight HCMV-seropositive donors. PBMC were incubated in culture medium alone (control) or were treated with the three indicated doses of HCMV for $3 \mathrm{~h}$. After washing, cells were cultured for $72 \mathrm{~h}$ before constituting cocultures with acutely HIV-1-infected PBMC. HIV-1 p24 antigen levels in coculture supernatants were determined for the indicated days. 
coculture, the maximal inducing dose of HCMV yielded $598 \pm 207 \mathrm{pg}$ p24 antigen $/ \mathrm{ml}$ in cocultures containing PBMC from the eight HCMV-seropositive donors compared with $27 \pm 10 \mathrm{pg} \mathrm{p} 24$ antigen/ml in cocultures from the eight HCMVseronegative donors $(P<0.01)$.

To determine whether another herpes group virus could also serve as an activation signal of HIV-1 replication in the PBMC coculture assay system, PBMC from three donors who were both HCMV-and VZV-seropositive were stimulated separately with $\mathrm{HCMV}\left(\mathrm{TCID}_{50} 10^{-3.5}\right)$ or $\mathrm{VZV}\left(\operatorname{TCID}_{50} 10^{-1}, 10^{-2}\right.$, and $10^{-3}$ ) for $3 \mathrm{~d}$ before constituting cocultures with HIV-infected PBMC. On day 4 of coculture, p24 antigen was detected in supernatants of cocultures containing PBMC from all three donors when HCMV was used as a stimulus $(650 \pm 117 \mathrm{pg} / \mathrm{ml})$, whereas the p24 antigen concentration was $<100 \mathrm{pg} / \mathrm{ml}$ in supernatants of all cocultures containing VZV-stimulated PBMC. By day 6 of coculture, however, HIV-1 replication was evident in cocultures containing VZV-stimulated PBMC from each of the three donors. With the maximal stimulating dose of $\operatorname{VZV}\left(10^{-2} \mathrm{TCID}_{50}\right)$, the p24 antigen levels in coculture supernatants were $565 \pm 236 \mathrm{pg} / \mathrm{ml}$ on day 6 and $992 \pm 352 \mathrm{pg} / \mathrm{ml}$ on day 7 of coculture; the p24 antigen level was $1538 \pm 99$ and $1800 \pm 100 \mathrm{pg} / \mathrm{ml}$ in the supernatants from cocultures containing HCMV-stimulated PBMC on day 6 and day 7 of coculture, respectively.

Cytokine release from $H C M V$-stimulated $P B M C$. The finding that PBMC from HCMV-seropositive but not from HCMV-seronegative donors were capable of inducing HIV-1 replication suggested that HCMV stimulates a differential release of cytokines from PBMC from these two donor groups. To test this hypothesis, PBMC from HCMV-seropositive and HCMV-seronegative donors were treated with HCMV for $3 \mathrm{~h}$, and levels of IL- $1 \beta$, IL- 6 , and TNF- $\alpha$ were measured in culture supernatants immediately after washing and after $2,18,48$, and $72 \mathrm{~h}$ of incubation. Results of cytokine determinations from the 18-h cultures are shown in Fig. 2. In contrast to the positive control, LPS, which acted as a potent stimulus of all three cytokines, HCMV elicited the release only of TNF- $\alpha$. Of note, levels of this cytokine above negative control values (culture medium alone) were found exclusively in the supernatants of PBMC cultures from each of the five HCMV-seropositive donors tested. This difference in HCMV-mediated TNF- $\alpha$ release from PBMC of HCMV-seropositive versus HCMV-seronegative donors was observed at each of the other culture times $(2,48$, and $72 \mathrm{~h})$, and although the maximal difference between values obtained with cells from seropositive and seronegative donors was observed at $18 \mathrm{~h}$, the TNF- $\alpha$ levels in coculture supernatants were still significantly $(P<0.05)$ elevated at $72 \mathrm{~h}$ $(56 \pm 22$ vs. $3 \pm 1 \mathrm{pg} / \mathrm{ml}$ in the seropositive and seronegative groups, respectively). Levels of IL- $1 \beta$ and IL-6 in supernatants of HCMV-treated cells were not significantly greater than negative control values at any culture time, and the amounts of all three cytokines released from PBMC that had been stimulated with LPS did not differ at any culture time when cells from the two donor groups were compared (data from the $18 \mathrm{~h}$ cultures are shown in Fig. 2).

Effect of anti-TNF- $\alpha$ antibodies on HIV-1 replication in acutely infected cells. On the basis of the results of the previous experiments, we postulated that TNF- $\alpha$ is a mediator of HCMV-induced replication in cocultures containing PBMC from HCMV-seropositive donors and acutely HIV-1-infected PBMC. To test this hypothesis, monoclonal anti-TNF- $\alpha$ anti-
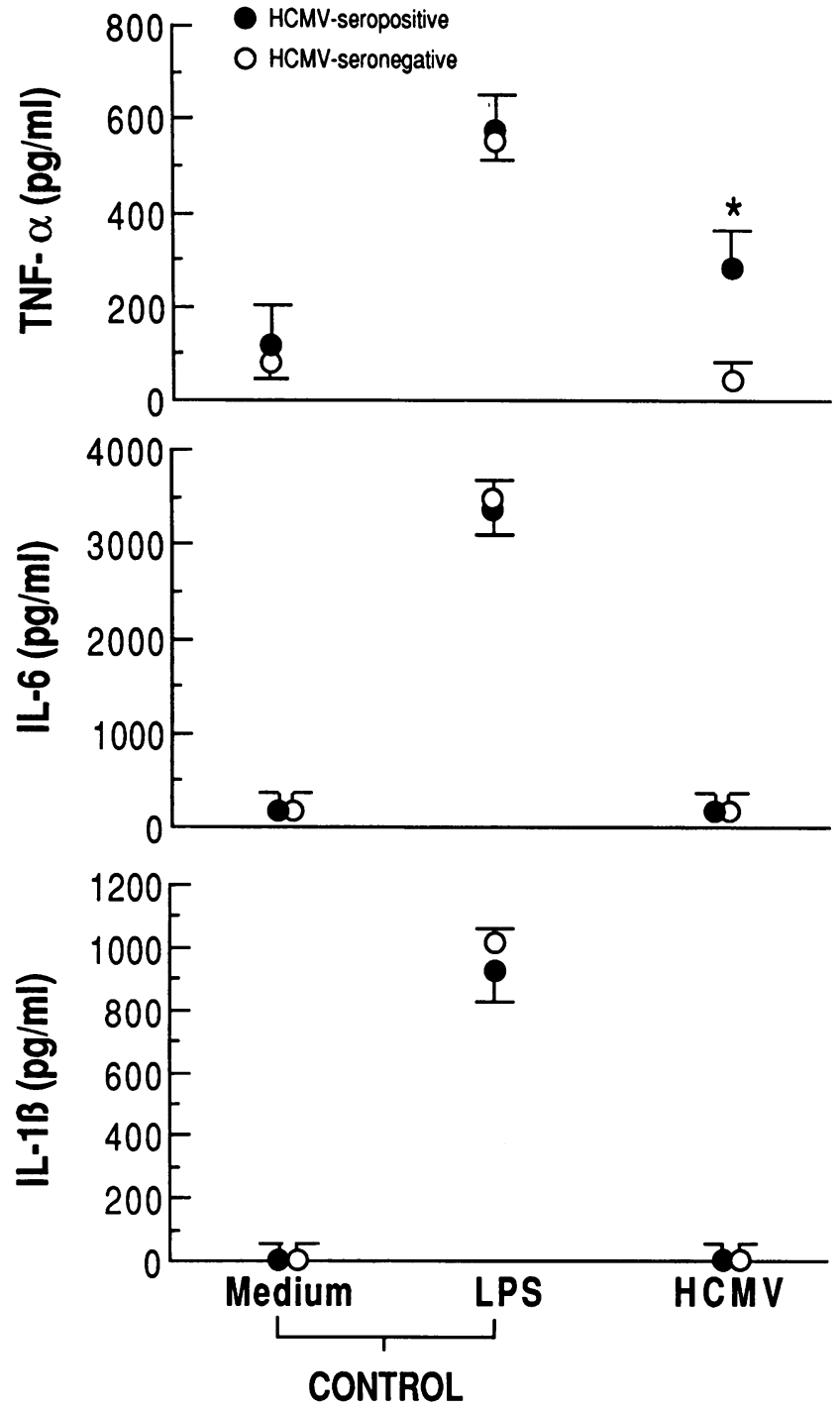

Figure 2. Cytokine release from HCMV-treated PBMC. PBMC from HCMV-seropositive $(n=5)$ and HCMV-seronegative $(n=4)$ donors were incubated for $3 \mathrm{~h}$ in culture medium alone, culture medium containing LPS $(1 \mathrm{ng} / \mathrm{ml})$, or HCMV $\left(10^{-3.5} \mathrm{TCID}_{50}\right)$. After washing, PBMC were cultured for $18 \mathrm{~h}$, and cytokines were measured in supernatants. Values are mean \pm SE. ${ }^{*} P<0.05$, compared with HCMV-seronegative value.

bodies were used as a means of blocking TNF- $\alpha$. Before introducing anti-TNF- $\alpha$ antibodies into the coculture system, a study was performed with the chronically infected U1 cell line alone to ascertain the concentration of antibodies needed to block TNF- $\alpha$-mediated viral expression. When U1 cells were treated with recombinant TNF- $\alpha\left(10^{-12} \mathrm{M}\right), 2,350 \mathrm{pg}$ HIV-1 p24 antigen/ $\mathrm{ml}$ was measured in the supernatant of day 3 cultures, and only $120 \mathrm{pg}$ p24 was detected in cultures lacking recombinant TNF- $\alpha$. Anti-TNF- $\alpha$ antibodies at dilutions of $1: 1,000(10 \mu \mathrm{g} / \mathrm{ml})$ and $1: 10,000$ reduced by over $90 \%$ the stimulatory effect of recombinant TNF- $\alpha$, whereas anti-TNF- $\alpha$ antibodies at a dilution of 1:100,000 and control monoclonal antibodies at all three dilutions had no inhibitory effect on recombinant TNF- $\alpha$-induced HIV-1 expression in U1 cell cultures (data not shown).

Next, we studied the effect of anti-TNF- $\alpha$ antibodies in cocultures of HCMV-stimulated PBMC added to acutely HIV-1- 

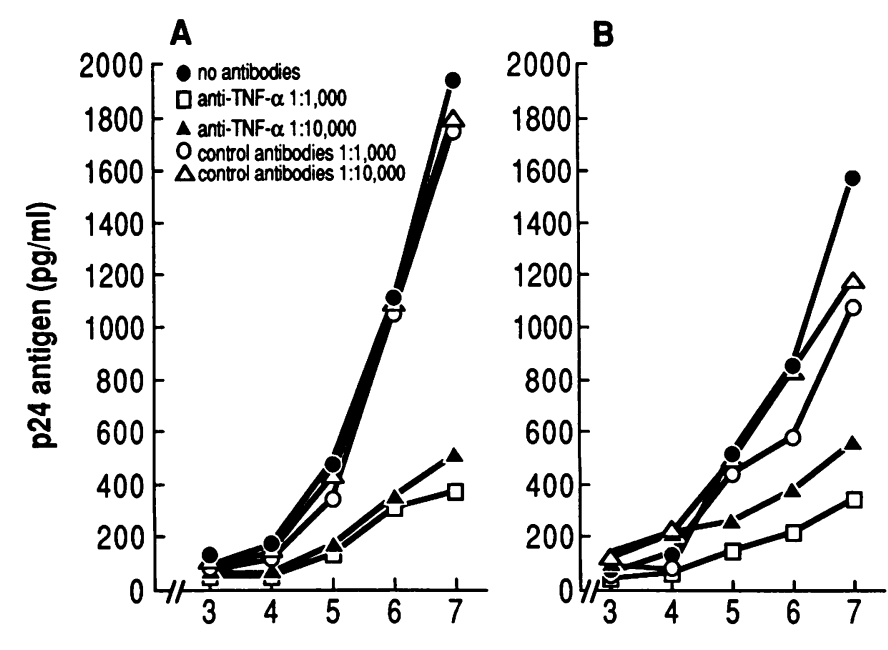

Days of Coculture

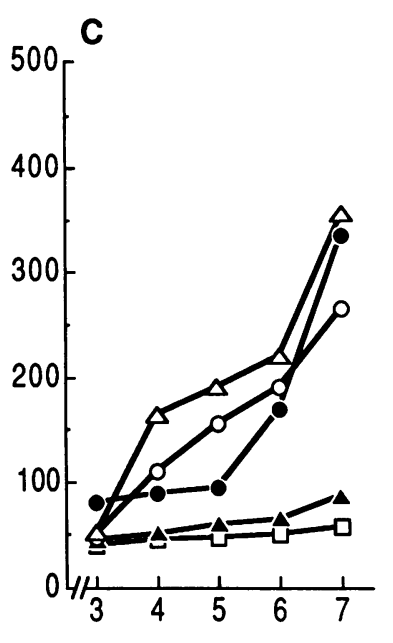

Figure 3. Inhibitory effect of antiTNF- $\alpha$ antibodies on HIV-1 replication in cocultures of HCMV-stimulated PBMC with acutely infected PBMC. PBMC from three HCMV-seropositive donors $(A-C)$ were treated with HCMV $\left(10^{-3.5} \mathrm{TCID}_{50}\right)$ in the absence (no antibodies) or presence of antiTNF- $\alpha$ or control antibodies, at the indicated dilutions, before constituting cocultures with acutely HIV-1infected PBMC. HIV-1 p24 antigen levels in coculture supernatants were determined for the indicated days. infected PBMC. In this coculture system, anti-TNF- $\alpha$ antibodies markedly inhibited the activity of HCMV-stimulated PBMC (Fig. 3). Although there was variability in the capacity of PBMC from individual HCMV-seropositive donors to induce HIV-1 replication, as had been documented in initial experiments (Fig. 1), the magnitude of the inhibitory effect of anti-TNF- $\alpha$ antibodies was similar with PBMC from each of the three HCMV-seropositive donors tested. When compared with control cocultures containing HCMV-stimulated PBMC that had not been treated with antibodies, the inhibition by anti-TNF- $\alpha$ antibodies $(1: 1,000)$ was $81 \pm 1 \%$ on day $7(F$ $=28.87, P<0.001)$. At a dilution of 1:10,000, anti-TNF- $\alpha$ antibodies were slightly less potent $(69 \pm 3 \%, P<0.01)$. Control antibodies, at both dilutions, did not block the HIV-1 replication induced by HCMV-stimulated PBMC (Fig. 3).

Effect of anti-TNF- $\alpha$ antibodies on HIV-I expression in chronically infected cells. To see if anti-TNF- $\alpha$ antibodies would also block the expression of HIV-1 in chronically infected cells induced by HCMV-stimulated PBMC, cocultures were constituted with the U1 cell line. Preliminary experiments determined that HCMV-stimulated PBMC from HCMV-seropositive donors triggered the expression of HIV-1 when these cells were added to U1 cells, whereas unstimulated control PBMC did not induce HIV-1 expression (data not shown). The induction of HIV-1 expression in U1 cells by HCMV-stimu- lated PBMC was reduced by anti-TNF- $\alpha$ antibodies but not by control antibodies (Fig. 4). When compared with control cocultures containing HCMV-stimulated PBMC that had not been treated with antibodies, the inhibition by $1: 1,000$ dilution of anti-TNF- $\alpha$ antibodies was $47 \pm 4 \%$ on day 5 of coculture ( $F$ $=33.01, P<0.01)$. A somewhat smaller inhibitory effect $(40 \pm 8 \%, P<0.05)$ was seen with the $1: 10,000$ dilution of specific antibodies, and control antibodies had no effect on HIV-1 expression in this coculture system (Fig. 4).

Effect of pentoxifylline on HIV-1 replication. The role of TNF- $\alpha$ as a mediator of HIV-1 replication next was assessed by treating HCMV-stimulated PBMC with pentoxifylline, a known inhibitor of TNF- $\alpha$ biosynthesis (15-18). Treatment of HCMV-stimulated PBMC with $100 \mu \mathrm{g} / \mathrm{ml}$ pentoxifylline resulted in a significant reduction of HIV-1 replication when these cells were cocultured with acutely infected PBMC (Fig. 5 $A$ ) or with the U1 cell line (Fig. $5 B$ ) (inhibition of 56 and 93\%, respectively, when compared with untreated control PBMC). In cocultures with $U 1$ cells, significant inhibition was observed at a pentoxifylline concentration as low as $1 \mu \mathrm{g} / \mathrm{ml}$ (Fig. $5 B$ ).

\section{Discussion}

In the present study, we found that TNF- $\alpha$ is a key mediator of HIV-1 replication in cocultures of HCMV-stimulated PBMC
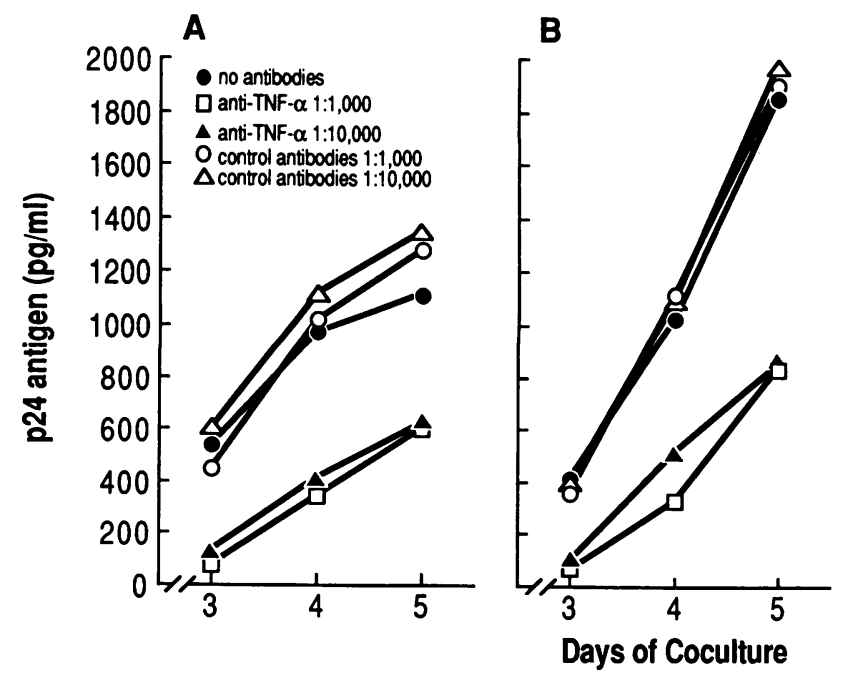

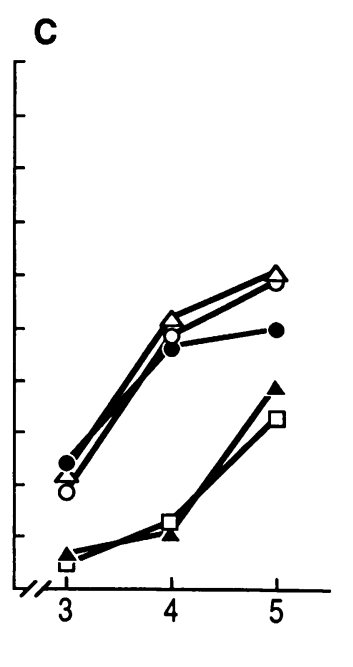

Figure 4. Inhibitory effect of anti-TNF- $\alpha$ antibodies on HIV-1 expression in U1 cells induced by HCMV-stimulated PBMC. PBMC from three HCMV-seropositive donors $(A-C)$ were treated with $\operatorname{HCMV}\left(10^{-3.5} \mathrm{TCID}_{50}\right)$ in the absence (no antibodies) or presence of anti-TNF- $\alpha$ or control antibodies, at the indicated dilutions, before constituting cocultures with U1 cells. HIV-1 p24 antigen levels in coculture supernatants were determined for the indicated days. 


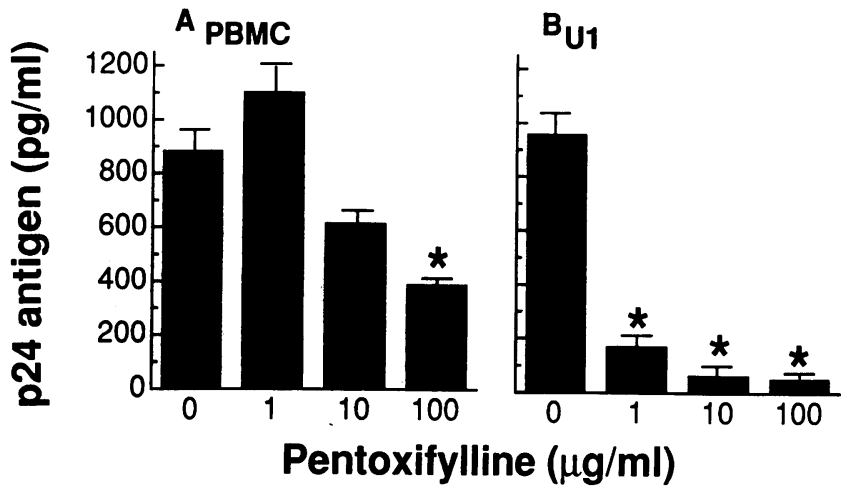

Figure 5. Inhibitory effect of pentoxifylline on HIV-1 replication induced by HCMV-stimulated PBMC in cocultures with acutely HIV1 -infected PBMC $(A)$ and U1 cells $(B)$. PBMC from three HCMVseropositive donors were treated with $\mathrm{HCMV}\left(10^{-3.5} \mathrm{TCID}_{50}\right)$ in the absence or presence of pentoxifylline, at the indicated concentrations, before constituting cocultures. HIV-1 p24 antigen levels in coculture supernatants were determined on day 7 in the acute infection system and on day 4 in the chronic infection system. Values are mean $\pm S E$. ${ }^{*} P<0.05$, compared with cocultures with no pentoxifylline.

and acutely HIV-1-infected PBMC. Similarly, TNF- $\alpha$ was shown to operate as a mediator of HIV-1 expression in the promonocytic line U1 when these chronically infected cells were cocultured with HCMV-stimulated PBMC. Direct evidence that HCMV can stimulate TNF- $\alpha$ release from PBMC was provided in an experiment with PBMC obtained from HCMV-seropositive donors. This latter finding appears to explain our initial observation that HCMV-stimulated PBMC from seropositive but not from seronegative donors can trigger HIV-1 replication in PBMC cocultures. Such a differential release of TNF- $\alpha$ could also explain the findings of Tremblay et al. (13) who showed that HCMV can directly stimulate HIV-1 replication in PBMC cultures from HIV-1-infected donors but only when the PBMC were obtained from subjects who were HCMV-seropositive.

Over the past few years, studies of in vitro models of HIV-1 infection have provided convincing evidence that TNF- $\alpha$, a cytokine produced primarily by activated monocytes and lymphocytes, plays an important role in the pathogenesis of HIV-1 (19). When added to cell cultures, TNF- $\alpha$ has been shown to upregulate HIV-1 expression in chronically infected T-cell ( 20 , 21) and monocytic cell (22) lines and to stimulate viral replication in acutely infected T lymphocytes (23) and monocytederived macrophages $(22,24)$. Also, TNF- $\alpha$ has been found to act as a mediator of HIV-1 expression in chronically infected cell lines stimulated with phorbol myristate acetate (25) or with supernatants from LPS-treated macrophages (26). TNF- $\alpha$ appears to induce HIV-1 gene expression in these cell lines by transcriptional mechanisms involving the activation of nuclear factor- $k B$ (27).

Although the results of the present study demonstrate that TNF- $\alpha$ plays a major role in the induction of HIV-1 replication by HCMV-stimulated PBMC, additional mechanisms could also be involved. In addition to TNF- $\alpha$, IL- 6 is known to upregulate the expression of HIV-1 in the U1 clone (22). Although we could not detect the release of IL-6 into the supernatants of HCMV-treated PBMC, it is still possible that IL-6, or other stimulatory cytokines (19), also triggers HIV-1 expres- sion in cocultures with HCMV-stimulated PBMC. The immediate early gene products of HCMV have been shown to be potent transactivators of HIV-1 gene expression $(28,29)$ which could represent a direct, cytokine-independent mechanism of enhanced HIV-1 replication. HCMV recently has been shown to induce receptors for the Fc portion of immunoglobulins on fibroblasts which facilitates HIV-1 infection of these cells (30). If HCMV were to increase Fc receptor expression on monocytes within PBMC cultures, then in the presence of antibodies to HIV-1, increased monocyte uptake of HIV-1 antibody complexes could represent another cytokine-independent mechanism of enhanced HIV-1 replication by HCMV (30).

HCMV is known to result in a non-productive or abortive infection when cultured with blood monocytes $(31,32)$. The disposition of this virus within the PBMC cultures used in the present study, which are comprised of monocytes and lymphocytes, is unknown, as is the precise sequence of events which leads to TNF- $\alpha$ release from these cells. The finding that only PBMC from HCMV-seropositive donors were responsive to HCMV suggests that the process involves cells which recognize or have memory of HCMV antigen. The cell culture medium used in these experiments contained serum with antibodies to HCMV. Whether specific antibodies are required for activation of PBMC from HCMV-seropositive individuals is unknown, and in future studies the influence of anti-HCMV and of anti-HIV-1 antibodies on HIV-1 replication in this coculture system will be explored. Since the genes for TNF- $\alpha$ and IL- $1 \beta$ are regulated independently, it is not surprising that HCMV did not elicit the release of IL-1 $\beta$. It should be pointed out, however, that other investigators have shown that the interaction of HCMV with PBMC from seronegative donors is associated with the production of an IL-1 inhibitor $(33,34)$ which may play an important role in the immunosuppressive properties of HCMV (35-37).

While the demonstration that HCMV can trigger TNF- $\alpha$ release from PBMC is a new finding, this capacity is known to be shared by other viruses $(38,39)$. Although initial studies suggested that HIV- 1 is also capable of triggering TNF- $\alpha$ release from PBMC (40), more recent work indicates that this is not the case (41-43). Contamination of viral preparations or culture medium with endotoxin could explain some of the earlier work with HIV-1, since endotoxin is both ubiquitous and a potent stimulus of TNF- $\alpha$. In the present study, the findings that HCMV yielded TNF- $\alpha$ and induced HIV-1 replication only when PBMC from HCMV-seropositive subjects were used argues against endotoxin being responsible for our findings.

While the biologic function of viral-induced TNF- $\alpha$ is not completely understood, the results of most studies indicate that TNF- $\alpha$ is involved in host defense against a wide variety of viruses (44-47), including HCMV (47). HIV-1, on the other hand, takes advantage of this host defense mechanism (19), and although HIV-1 does not appear to initiate production of TNF- $\alpha$, opportunistic microorganisms which can do so, such as HCMV, may in the process be serving the purposes of HIV1. The finding in the present study that another herpes group virus, namely, VZV, can also trigger HIV-1 replication in PBMC cocultures indicates that HCMV is not unique in this regard. Although serious VZV infections have been reported in HIV-infected patients (48), and herpes zoster may herald the development of AIDS (49), nevertheless, HCMV disease is the 
most common opportunistic viral infection in patients with AIDS and has been recognized as a major source of morbidity and mortality in these patients (2-5).

Currently, the mainstay of therapy of HIV-1-infected patients is use of antiviral agents that interfere directly with critical viral enzymes, such as, reverse transcriptase. Another treatment strategy being explored is use of immunomodulators. The observation in the present study that the methylxanthine drug pentoxifylline, which is a known inhibitor of TNF- $\alpha$ mRNA (15-18), can block HIV-1 replication induced by HCMV-stimulated PBMC is consistent with a recent report by other investigators who studied mitogen-stimulated PBMC (18). Whether agents which interfere with the production or activity of TNF- $\alpha$, such as, pentoxifylline or anti-TNF- $\alpha$ monoclonal antibodies, have any clinical benefit in HIV-1-infected patients awaits the results of carefully controlled clinical trials.

\section{Acknowledgments}

We gratefully acknowledge the assistance of Al Pheley, Ph.D. for statistical support and of Beth Olson for help in preparation of the manuscript.

This work was supported by United States Public Health Service grants DA-04381 and AI-27661.

\section{References}

1. Haverkos, H. W. 1987. Factors associated with the pathogenesis of AIDS. $J$. Infect. Dis. 156:250-257.

2. Drew, W. L. 1988. Cytomegalovirus infection in patients with AIDS. $J$. Infect. Dis. 158:449-456.

3. Jacobson, M. A., and J. Mills. 1988. Serious cytomegalovirus disease in the acquired immunodeficiency syndrome (AIDS): clinical findings, diagnosis, and treatment. Ann. Intern. Med. 108:585-594.

4. Schooley, R. 1990. Cytomegalovirus in the setting of infection with human immunodeficiency virus. Rev. Infect. Dis. 12(Suppl.):811-819.

5. Holmberg, S. D., A. R. Gerber, J. A. Stewart, F. K. Lee, P. M. O'Malley, and A. J. Nahmias. 1988. Herpesviruses as co-factors in AIDS. Lancet. i:746-747.

6. Lang, D. J., A. A. S. Kovacs, J. A. Zaia, G. Doelkin, J. C. Niland, L. Aledort, S. P. Azen, M. A. Fletcher, J. Gauderman, G. J. Gjerset, et al. 1989. Seroepidemiologic studies of cytomegalovirus and Epstein-Barr virus infections in relationship to human immunodeficiency virus type 1 in selected populations. J. Acquired Immune Defic. Syndr. 2:540-549.

7. Webster, A., C. A. Lee, D. G. Cook, J. E. Grundy, P. B. A. Kernoff, and P. D. Griffiths. 1989. Cytomegalovirus infection and progression towards AIDS in haemophiliacs with human immunodeficiency virus infection. Lancet. i:6366.

8. Laurence, J. 1990. Molecular interactions among herpesviruses and human immunodeficiency viruses. J. Infect. Dis. 162:338-346.

9. Webster, A. 1991. Cytomegalovirus as a possible cofactor in HIV disease progression. J. Acquired Immune Defic. Syndr. 4(Suppl.):47-52.

10. Skolnik, P. R., B. R. Kosloff, and M. S. Hirsch. 1988. Bidirectional interactions between human immunodeficiency virus type 1 and cytomegalovirus. $J$. Infect. Dis. 157:508-514.

11. Clouse, K. A., F. B. Robbins, B. Fernie, J. M. Ostrove, and A. S. Fauci. 1989. Viral antigen stimulation of the production of human monokines capable of regulating HIV-1 expression. J. Immunol. 143:470-475.

12. Casareale, D., M. Fiala, C. M. Chang, L. A. Cone, and E. S. Mocarski. 1989. Cytomegalovirus enhances lysis of HIV-infected T lymphoblasts. Int. J. Cancer. 44:124-130.

13. Tremblay, M., M. Gornitsky, and M. A. Wainberg. 1989. Active replication of human immunodeficiency virus type 1 by peripheral blood mononuclear cells following coincubation with herpes viruses. J. Med. Virol. 29:109-114.

14. Peterson, P. K., B. M. Sharp, G. Gekker, P. S. Portoghese, K. Sannerud, and H. H. Balfour, Jr. 1990. Morphine promotes the growth of HIV-1 in human peripheral blood mononuclear cell cocultures. AIDS (Phila.). 4:869-873.

15. Streiter, R. M., D. G. Remick, P. A. Ward, R. N. Spengler, J. P. Lynch III, J. Larrick, and S. L. Kunkel. 1988. Cellular and molecular regulation of tumor necrosis factor-alpha production by pentoxifylline. Biochem. Biophys. Res. Commun. 155:1230-1236.

16. Han, J., P. Thompson, and B. Beutler. 1990. Dexamethasone and pentox- ifylline inhibit endotoxin-induced cachectin/tumor necrosis factor synthesis at separate points in the signaling pathway. J. Exp. Med. 172:391-394.

17. Endres, S., H.-J. Fülle, B. Sinha, D. Stoll, C. A. Dinarello, R. Gerzer, and P. C. Weber. 1991. Cyclic nucleotides differentially regulate the synthesis of tumour necrosis factor- $\alpha$ and interleukin- $1 \beta$ by human mononuclear cells. Immunology. 72:56-60.

18. Fazely, F., B. J. Dezube, J. Allen-Ryan, A. B. Pardee, and R. M. Ruprecht. 1991. Pentoxifylline (Trental) decreases the replication of the human immunodeficiency virus type 1 in human peripheral blood mononuclear cells and in cultured T cells. Blood. 77:1653-1656.

19. Fauci, A. S. 1990. Cytokine regulation of HIV expression. Lymphokine Res. 9:527-531.

20. Folks, T. M., K. A. Clouse, J. Justement, A. Rabson, E. Duh, J. H. Kehrl, and A. S. Fauci. 1989. Tumor necrosis factor $\alpha$ induces expression of human immunodeficiency virus in a chronically infected T-cell clone. Proc. Natl. Acad. Sci. USA. 86:2365-2368.

21. Kobayashi, N. 1989. Cytocidal effect of tumor necrosis factor on cells chronically infected with human immunodeficiency virus (HIV): enhancement of HIV replication. J. Virol. 63:2504-2509.

22. Poli, G., P. Bressler, A. Kinter, E. Duh, W. C. Timmer, A. Rabson, J. S. Justement, S. Stanley, and A. S. Fauci. 1990. Interleukin 6 induces human immunodeficiency virus expression in infected monocytic cells alone and in synergy with tumor necrosis factor $\alpha$ by transcriptional and post-transcriptional mechanisms. J. Exp. Med. 172:151-158.

23. Vyakarnam, A., J. McKeating, A. Meager, and P. C. Beverly. 1990. Tumor necrosis factors $(\alpha, \beta)$ induced by HIV-1 in peripheral blood mononuclear cells potentiate virus replication. AIDS (Phila.). 4:21-27.

24. Mellors, J. W., B. P. Griffith, M. A. Ortiz, M. L. Landry, and J. L. Ryan. 1991. Tumor necrosis factor- $\alpha /$ cachectin enhances human immunodeficiency virus type 1 replication in primary macrophages. $J$. Infect. Dis. 163:78-82.

25. Poli, G., A. Kinter, J. S. Justement, J. H. Kehrl, P. Bressler, S. Stanley, and A. S. Fauci. 1990. Tumor necrosis factor $\alpha$ functions in an autocrine manner in the induction of human immunodeficiency virus expression. Proc. Natl. Acad. Sci. USA. 87:782-785.

26. Clouse, K. A., D. Powell, I. Washington, G. Poli, K. Strebel, W. Farrar, P. Barstad, J. Kovacs, A. S. Fauci, and T. M. Folks. 1989. Monokine regulation of human immunodeficiency virus-1 expression in a chronically infected $\mathrm{T}$ cell clone. J. Immunol. 142:431-438.

27. Duh, E. J., W. J. Maury, T. M. Folks, A. S. Fauci, and A. B. Rabson. 1989. Tumor necrosis factor alpha activates human immunodeficiency virus type 1 through induction of nuclear factor binding to the NF-kappa B sites in the long terminal repeat. Proc. Natl. Acad. Sci. USA. 86:5974-5978.

28. Davis, M. G., S. C. Kenney, J. Kamine, J. P. Pagano, and E.-S. Huang. 1987. Immediate-early gene region of human cytomegalovirus trans-activates the promoter of human immunodeficiency virus. Proc. Natl. Acad. Sci. USA. 84:8642-8646.

29. Burry, P. A., E. Pratt-Lowe, D. J. Alcendor, R. E. Unger, and P. A. Luciw. 1990. Molecular interactions between human immunodeficiency virus type 1 and human cytomegalovirus. Ann. NY Acad. Sci. 616:54-63.

30. McKeating, J. A., P. D. Griffiths, and R. A. Weiss. 1990. HIV susceptibility conferred to human fibroblasts by cytomegalovirus-induced Fc receptor. $\mathrm{Na}$ ture (Lond.). 343:659-661.

31. Rice, G. P. A., R. D. Schrier, and M. B. A. Oldstone. 1984. Cytomegalovirus infects human lymphocytes and monocytes: virus expression is restricted to immediate-early gene products. Proc. Natl. Acad. Sci. USA. 81:6134-6138.

32. Einhorn, L., and Å. Öst. 1984. Cytomegalovirus infection of human blood cells. J. Infect Dis. 149:207-214.

33. Rodgers, B. C., D. M. Scott, J. Mundin, and J. G. P. Sissons. 1985. Monocyte-derived inhibitor of interleukin 1 induced by human cytomegalovirus. J. Virol. 55:527-532.

34. Moses, A. V., and H. M. Garnett. 1990. The effect of human cytomegalovirus on the production and biologic action of interleukin-1. J. Infect. Dis. 162:381-388.

35. Carney, W. P., and M. S. Hirsch. 1981. Mechanisms of immunosupression in cytomegalovirus mononucleosis. II. Virus-monocyte interactions. J. Infect. Dis. 144:47-54.

36. Dudding, L. R., and H. M. Garnett. 1987. Interaction of strain AD169 and a clinical isolate of cytomegalovirus with peripheral monocytes: the effect of lipopolysaccharide stimulation. J. Infect. Dis. 155:891-896.

37. Kapasi, K., and G. P. A. Rice. 1988. Cytomegalovirus infection of peripheral blood mononuclear cells: effects on interleukin- 1 and -2 production and responsiveness. J. Virol. 62:3603-3607.

38. Goldfeld, A. E., and T. Maniatis. 1989. Coordinate viral induction of tumor necrosis factor $\alpha$ and interferon $\beta$ in human B cells and monocytes. Proc. Natl. Acad. Sci. USA. 86:1490-1494.

39. Nain, M., F. Hinder, J.-H. Gong, A. Schmidt, A. Bender, H. Sprenger, and D. Gemsa. 1990. Tumor necrosis factor- $\alpha$ production of influenza A virus-in- 
fected macrophages and potentiating effect of lipopolysaccharides. J. Immunol. 145:1921-1928.

40. Merrill, J. E., Y. Koyanagi, and I. S. Y. Chen. 1989. Interleukin-1 and tumor necrosis factor $\alpha$ can be induced from mononuclear phagocytes by human immunodeficiency virus type 1 binding to the CD4 receptor. J. Virol. 63:44044408.

41. Munis, J. R., D. D. Richman, and R. S. Kornbluth. 1990. Human immunodeficiency virus- 1 infection of macrophages in vitro neither induces tumor necrosis factor (TNF)/cachectin gene expression nor alters TNF/cachectin induction by lipopolysacchride. J. Clin. Invest. 85:591-596.

42. Molina, J.-M., D. T. Scadden, C. Amirault, A. Woon, E. Vannier, C. A. Dinarello, and J. E. Groopman. 1990. Human immunodeficiency virus does not induce interleukin-1, interleukin-6, or tumor necrosis factor in mononuclear cells. J. Virol. 64:2901-2906.

43. Goldfeld, A. E., K. Birch-Limberger, R. T. Schooley, and B. D. Walker. 1991. HIV-1 infection does not induce tumor necrosis factor- $\alpha$ or interferon- $\beta$ gene transcription. J. Acquired Immune Defic. Syndr. 4:41-47.

44. Wong, G. H. W., and D. V. Goeddel. 1986. Tumor necrosis factors $\alpha$ and $\beta$ inhibit virus replication and synergize with interferons. Nature (Lond.). 323:819-822.

45. Van Damme, J., M. DeLey, J. Van Snick, C. A. Dinarello, and A. Billiau. 1987. The role of interferon- $\beta_{1}$ and the $26-\kappa$ Da protein (interferon $-\beta_{2}$ ) as mediators of the antiviral effect of interleukin 1 and tumor necrosis factor. J. Immunol. 139:1867-1872.

46. Mestan, J., M. Brockhaus, H. Kirchner, and H. Jacobsen. 1988. Antiviral activity of tumor necrosis factor. Synergism with interferons and induction of oligo-2', 5'-adenylate synthetase. J. Gen. Virol. 69:3113-3120.

47. Paya, C. V., N. Kenmotsu, R. A. Schoon, and P. J. Leibson. 1988. Tumor necrosis factor and lymphotoxin secretion by human natural killer cells leads to antiviral cytotoxicity. J. Immunol. 141:1989-1995.

48. Cohen, P. R., V. P. Beltrani, and M. E. Grossman. 1988. Disseminated herpes zoster in patients with human immunodeficiency virus infection. Am. J. Med. 84:1076-1080.

49. Melbye, M., R. J. Grossman, J. J. Goedert, M. E. Eyster, and R. J. Biggar. 1987. Risk of AIDS after herpes zoster. Lancet. ii:1113-1115. 